MUZIKOLOSKKI ZBORNIK - MUSICOLOGICAL ANNUAL XIII, LJUBLJANA 1977

UDK 78.083.5I(497.12) Lipovšek: 781.6

\title{
OBLIKOVALNI KONCEPT RAPSODIJ M. LIPOVŠKA
}

Monika Kartin-Duh (Ljubljana)

V bogatem komornem opusu Marijana Lipovška zavzemata posebno mesto dve rapsodiji za violino in klavir. Prva je nastala leta 1955, druga sedem let pozneje. $V$ obeh Lipovšek sledi značilnostim oblikovne gradnje, ki jo je razvil Béla Bartók oziroma pred njim že Franz Liszt. Bartókovi violinski rapsodjji sta dvodelni; prvi del je počasen, drugi hitrejši in razgibanejši. Lipovšek pa je dvodelnost razširil in dodal srednji del, ki je $\mathrm{v}$ tempu $\mathrm{v}$ obeh rapsodijah hitrejši od prvega in počasnejši od tretjega dela. Srednji del predstavlja med obema prehod. V prvem in tretjem de. lu pa najdemo tudi notranjo trodelnost. Tuai osnovno glasbeno tkivo Lipovšek navezuje na bistveno značilnost rapsodije. Vodilni motivični material črpa iz ljudskega glasbenega gradiva in tako mu $\mathrm{v}$ obeh rapsodijah služijo za jedro slovenske ljudske pesmi. Verdar jih $\mathrm{v}$ poteku tako bo gato, nenavadno in kvalitetno modificira, da posamezne pesmi le $\mathrm{z}$ veliko težavo prepoznamo. Metrično in melodično jih z najrazličnejšimi postopki izredno domiselno preobrazi, vendar nikdar ne zanika njihovega osnovnega bistva. Vešč poudarja njihove posebnosti in kvalitete ter zglajuje ljudsko preprosto oblikovana mesta, posebno zaključke. Druga rapsodija je bila pozneje tudi orkestrirana.

Prvi del prve rapsodije sestoji iz dveh pesmi v obliki A B A. Prvih osem taktov je modificirana oblika slovenske ljudske pesmi "Vsi so venci bejli». Nato sledi šest taktov samostojnega razvijanja osnovne motivike; ta se razširi še s štirimi takti ponovitve prvega stavka prve periode, ki predstavljajo izrazni umik v osnovno misel. $\mathbf{S}$ tem je podana dvodelnost, ki sestavlja del A. Značilna in zanimiva je basovska spremljava klavirja. Grajena je ostinatno, vendar ne v strogem smislu. Razvija se $v$ globino skladno $\mathrm{z}$ naraščanjem violinskega parta $\mathrm{v}$ višino. Melodija ljudske pesm1 je dobila $\mathrm{v}$ zapisu korone, ki niso določljive, tu pa so točno določene $z$ različnimi metrumi. Prvič zato, ker so vsi vrinjeni predtakti spojeni v kompletne cele takte in zato, ker se tudi sicer metrum zaradi modifikacije melodije premika $z$ druge dobe na drugo taktovo dobo. Melodija ljudske pesmi je brez takta, oziroma tudi $v$ njej zaradi zadržanih koron nastajajo mešani takti. Violinski in klavirski part se metrično dopolnjujeta, 
zarađi nenehnih premikov akcentov na različne taktove dobe pa pride tok spremljave $\mathrm{v}$ asimetrijo, kar je bil Lipovškov namen. Motivika v violini je na tem mestu zgrajena tako, da je $s$ podaljšano ali dodano motiviko $\mathrm{v}$ svojem horizontalnem razvoju sicer asimetricna, glavni akcenti pa so vedno na težkih dobah.

B del je prosto uporabljen vzhodnoštajerski ljudski napev «Zunaj je suša» (Vün je süša). V metrumu je enotnejši od dela $A$, šele po sedmih taktih se namesto $2 / 4$ pojavi $3 / 4$ takt. Toda le $\mathrm{v}$ enem taktu, kajti zopet najdemo $\mathrm{v}$ naslednjih devetih taktih $2 / 4$ takt. Metrično je modifikacija precej prilagojena izvirniku, razen sklepa prve periode, in nima nobenih spremenjenih taktov; pač pa je ritem deljen med osminsko triolo in navadne osminke. Poleg tega je razpon melodične linije skoraj tri oktave, cesar $\mathrm{v}$ originalni pesmi ne najdemo. Medtem ko se je del A gibal večinoma $\mathrm{v}$ srednji in nizki legi violine $\mathrm{z}$ dvoprijemi, se giblje prva polovica $B$ dela $\mathrm{v}$ visoki legi, druga pa pretežno $\mathrm{v}$ nizki legił Zanimiva je kklavirska spremljava. Poteka $\mathrm{v}$ glavnem $\mathrm{v}$ intervalih terc, kvart, septim in sekund vzporedno $\mathrm{v}$ obeh rokah tako, da $\mathrm{v}$ prosti tonalnosti harmonsko dopolnjuje vodilno melodijo $\mathrm{v}$ violini. Skoraj vsaki taktovi dobi predstoji appoggiatura, ki celotno glasbeno tkivo presenetljivo barva.

Prehod od B k A delu predstavljajo štirje takti solo klavirja, ki prinašajo motivični material iz obeh delov. Harmonsko se giblje $v$ okviru b-mola; $v$ to melodijo, po formalnih odstavkih nedoločeno, vstopi violina z dvoprijemi čiste teme A, ki se tu prosto ponovi. Spremljava je sestavljena iz močnih intervalov. Prihaja do sočasnega razvoja dveh horizontalnih linij, od katerih je vsaka samostojna. Nekatera sozvočja so rezultat tradicionalne harmonije tujih tonov, ki jih je mogoče, upoštevajoc nekatere alteracije, $\mathrm{v}$ tonalnih zvezah obrazložiti. Druge disonance razultirajo iz samostojne linije obeh melodij in niso razpoložljive iz tonalnih izhodišč, temveč izhajajo iz melodične linije in se nanašajo le na horizontalne postope. Na koncu vsakega formalnega stavka Lipovšek vedno teži $\mathrm{k}$ smiselnemu sklepu, ki ga predstavlja temeljni akord tistega odstavka Po devetih taktih sledi vrhunec celotnega prvega dela A B A. Višek je podan $\nabla$ devetih taktih s ponovitvijo dveh taktov zadnjega motiva violine $\mathrm{v}$ klavirju. Klavirski part je samostojna kontrapunktična spremljava, ki se harmonsko ujema $\mathrm{z}$ violino; odvija se večinoma $\mathrm{v}$ oktavnem razmerju $\mathrm{v}$ sinkopiranem ritmu in se pojavlja tako svobodno kot kaže razvoj harmonskih zvez. Na koncu se v obeh zaključnih taktih bas umiri v ostinatu in tako se prične prav z njim del C. Tonalno se ostinatna spremljavja pojavi $\mathbf{v}$ navideznem c-molu, vendar je le-ta lebdeč in ni tonalno zanesljiv (namesto tona as nastopi ton a). Omenjeno je zaradi večje harmonske barvitost1 nastalo gotovo namenoma. Melodična linija violine je transformacija prve teme dela A.

C del predstavlja modifikacijo koroškega napeva "Zakaj se ti dečva ne vdašı. Napev je metrično zelo kompliciran, skladatelj pa se je odločil za 4/4 metrum, toda $s$ tem, da se metrični poudarki nenehno premikajo z dobe na dobo. Originalni napev je $\mathrm{v}$ lihem taktu, Lipovšek pa se je odločil za sodi takt. Opustil je vse morebitne fermate, ki se v ljudskem 
napevu sicer pojavljajo. Drugo in četrto osminsko dobo $\mathrm{v}$ originalu je tu zamenjal $\mathrm{z}$ dvema šestnajstinkama.
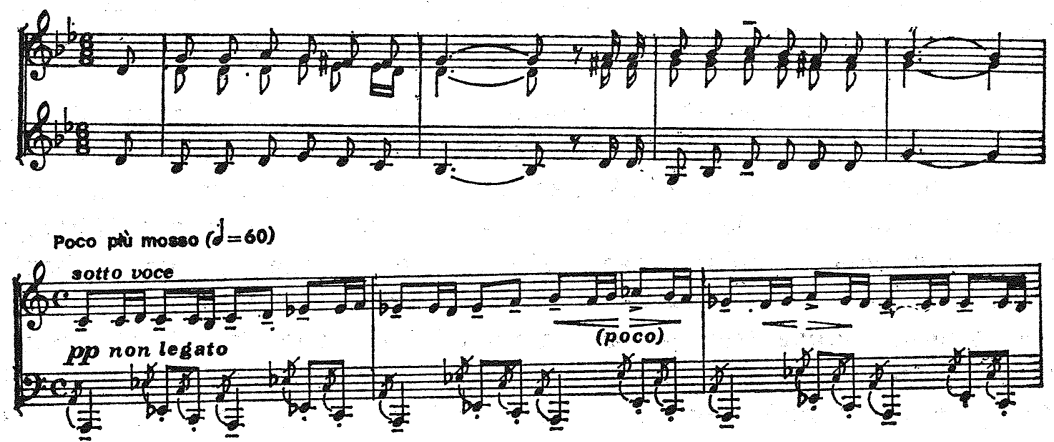

$\mathrm{Z}$ ritmično spremembo je opustil kadenco $\mathrm{v}$ vsakem dvotaktju in $\mathrm{s}$ tem dobil strnjena dvotaktja, ki se nadaljujejo neposredno po opisani motivični spremembi drugo za drugim. Prva perioda je sestavljena iz devetih taktov, $\mathrm{v}$ katerih se melodija $\mathrm{v}$ violini razvije tako, da se premika $\mathrm{v}$ višje tonske stopnje. Prvi višek je na tonu as, drugi na $f$, tretji na $d$, nato seže na es in ges. Po dveh in pol taktih se sklepni motiv združi oziroma ima vlogo ponovljenega začetnega motiva. To je obenem spojitev $\mathbf{s}$ ponovnim začetkom. Razlika je edino $\mathrm{v}$ tem, da prej prva težka doba sedaj pade na tretjo in prej četrta po vrsti je sedaj na drugi dobi. Ta del se $\mathrm{v}$ tej prvotni obliki konča na naslednji prvi dobi, medtem ko se je prej na tretji. Do številke 9 motivika ritmično v glavnem ni spremenjena, vendar se širi $\mathrm{v}$ tonsko višino. Ostinato $\mathrm{v}$ spremljavi je do tu skoraj dosleden. Razvija se $\mathrm{v}$ basu $\mathrm{z}$ oktavnim predložkom $\mathrm{v}$ ritmičnem obrazcu dve osminki in cetrtinka. Obratno od violinske teme, ki se odvija $v$ višje tone, pa tendira ostinatna spremljava navzdol s spodnjimi toni a, as, $g$, fis, $f$, es. V desni roki spremljave melodika delno podpira, delno dopolnjuje osnovno in glavno melodijo violine. Druga perioda je sestavljena iz drob. cev prejšnje motivike. Teh sedem taktov je instrumentalno in ritmično Lipovšek izredno razvil. Ritmično predvsem $\mathrm{s}$ kratkimi pavzami in $\mathrm{z}$ nenehnimi premiki poudarkov (predvsem $\mathrm{v}$ zadnjih štirih taktih). Motiv se premika $\mathrm{z}$ dobe na dobo, konstanta pa so osminke $\mathrm{v}$ basovski spremljavi. Premišljena je klavirska vloga desne roke, kajti odvija se strogo komplementarno $\mathrm{z}$ violinsko melodijo. To daje celotnemu tkivu veliko napetost. Po omenjenih sedmih taktih sledi delno spremenjena ponovitev in tonalna razširitev prve periode $\mathbf{C}$ dela. Pri gradnji melodične linije se pojavijo oziroma ponovijo nekateri motivi; $s$ tem skladatelj pripelje posamezne motive $\mathrm{v}$ višjo lego in jih obenem razširja. Motivi, ki segajo drug $\mathrm{v}$ drugega, se od viška sekvenčno ponovijo navzdol. Spremljava se ritmično skoraj podreja glavni violinski tematiki in jo harmonsko podpira. Sedaj prevzame vodilno vlogo klavir. $\mathrm{V}$ desni roki se pojavi augmentirana tema C dela, ki se razvije $v$ desetih in še naslednjega pol takta, nato sledi prehod in ponovitev te teme, prav tako augmentirane, $\mathrm{v}$ basu $\mathrm{v}$ naslednjih osmih 
taktih $\mathrm{z}$ izstopom $\mathrm{v}$ deveti takt. Ritmično ozadje je enakomerno osminsko gibanje najprej $\mathrm{v}$ basovski in nato $\mathrm{v}$ sopranski spremljavi. To so tritonska sozvočja, ves cas zgrajena $\mathrm{v}$ prosti tonalnosti $\mathrm{z}$ drugo roko. Violina ima nevezano novo melodiko, ki je $\mathrm{v}$ smiselnem razmerju do teme $\mathrm{v}$ spremljavi. Deloma je grajena sekvenčno in je pravzaprav opisovanje ostinatnih akordov $\mathrm{v}$ spremljavi desne roke, ki so večinoma nonakordi. $\mathrm{V}$ taktu pred številko 13 nastopi nenadna modulacija $\mathrm{v}$ a-mol, $\mathrm{s}$ katerim tudi začne, stevilka 13. To je presenetljivo, ker se prej vse odvija $v$ območju nižajev'. Omenjena številka predstavlja prehod od $\mathrm{C}$ dela $\mathrm{k} \mathrm{D}$ delu. Sestavlja ga motivika $\mathrm{C}$ dela, ki $\mathrm{s}$ pospešenim tempom preide $\mathrm{v} \mathrm{D}$ del. Violina prinese motivične drobce transformiranega koroškega napeva, klavirska spremljava jo komplementarno dopolnjuje. Violinski part imitira tako, da so violinski motivi v klavirju točno ponovljeni po notah, ne pa po metričnih akcentih oziroma to ritmično raznovrstnost povzročajo tudi različni zacetki enkrat $\mathrm{s}$ koncem zgornjega motiva, drugič za koncem omenjenega motiva. Tako se vodilna in spremljajoča linija komplementarno dopolnjujeta, a vselej različno. Basovski ostinato, ki se pojavi že dva takta pred stevilko $14 \mathrm{~s}$ figuro na tonih $\mathrm{g}$ a $\mathrm{g}$.

Prva tema $\mathrm{D}$ dela je modifikacija ljudskega napeva "Dolenjski furmaniu. Originalna pesem je v $5 / 4$ taktu in v spremenjenem citatu je skladatelj obdržal to taktovo mero. Edina razlika je $v$ tem, da je motiviko razsiril in delno ponovil. S tem je oplemenitil preprosto obliko sklepa ljudske pesmi. Tema se pojavi najprej $\mathrm{v}$ violini ob rahlo spremenjenem ostinatnem gibanju v spremljavi klavirja. Po štirih taktih sledi prehod, nato se tema prenese $\mathrm{v}$ klavir, violina pa prevzame vlogo spremljave $\mathrm{v}$ obliki prostega kontrapunkta $\mathrm{h}$ glavni melodiki. $\mathrm{V}$ naslednjih šestih taktih se motivika nadalje svobodno razvija $\mathrm{v}$ violinskem partu, prav tako je tudi klavirska spremljava neprimerno bolj razgibana kot je bila ob prvem nastopu teme "Dolenjskih furmanovu. Glasbeno tkivo se v nadaljevanju še bolj koncentrira $\mathrm{s}$ tem, da avtor $\mathrm{v}$ vedno krajših delih vizdeluje» motiviko furmanov; ker je tema po naravi plesno skercozna, je transformirana in izdelana v različnih podobah, ki se sicer dopolnjujejo, si pa vendarle kontrastirajo. Motivične drobce si violina in klavirski part nenehno podajata, delno jih razvijata istočasno. Zanimiva je tudi metrična sprememba: po štirih taktih, kjer se metrum kar dvakrat spremeni, se ustali $3 / 4$ takt. Osnovna tematika pa je razbita tudi $\mathrm{s}$ pasažami $\mathrm{v}$ desni roki spremljave in violinskem partu, dokler celotna tonska slika ne modulira v C-dur, v katerem se dvakrat pojavi citat teme, nato pa sledi kanon med violino in klavirjem, ki vsebuje elemente osnovne teme, le da je vedno pretrgan s kratkim sestnajstinskim gibanjem, ki pa vselej vsebuje melodično noto teme. Po malo skrajšani svobodni ponovitvi omenjenega dela se pojavi osnovna melodika, tokrat opisana $\mathrm{v}$ šestnajstinskem gibanju $\mathrm{v}$ violini, klavirski part pa prinese delno spremenjeno tematiko $\mathrm{v}$ osminskem toku $\mathrm{z}$ dodatnima dvema osminkama. Pred številko 24 je prehod petih taktov $v$ del, kjer se $\mathrm{v}$ violini pojavi zametek poznejše ljudske plesne melodije. Spremljavo sestavljajo sekvenčno se ponavljajoče figure $\mathrm{v}$ obeh rokah, ki vedno dopolnjujejo osminko $\mathrm{v}$ violinskem partu, vendar pa ne nastopajo samo $\mathrm{s}$ 
to notno vrednostjo. Plesno temo predstavljajo štirje takti šstnajstinskih pasaž, ki so v klavirju, nato jih prevzame violina, pa zopet klavir. Zaključek je skupen. Spremljava kontrapunktsko dopolnjuje glavno temo. Po kratkem prehodu, kjer je izvršena modulacija iz Des-dura v D-dur, se zacneta tema "Dolenjskih furmanov" in plesne melodije pojavljati skupno, $\mathbf{s}$ čimer Lipovšek doseže koncentracijo glasbenega tkiva in $\mathbf{s}$ tem daje slutiti bližajočo se codo. Tema furmanov se pojavi $\mathrm{v}$ klavirju, violina jo dopolnjuje z malo spremenjenim plesnim motivom. Nato si instrumenta vlogi zamenjata. Pri številki 29 nastopi zaključni del, kjer je najpreji v violini opisano kanonsko gibanje iz že znanega tonskega gradiva. To je zadnji sklep celotnega tkiva Dolenjskih furmanov; sledi zaključk in uvod $\mathrm{v}$ plesno temo. Nenehna menjava metruma sledi iz konteksta melodike, kjer se $\mathrm{z}$ izpuščanjem prej ponavljajočih se motivov melodija krči; $\mathbf{s}$ tem dosega skladatelj močno koncentracijo, kar omogoča velik efekt. Spremljava smiselno izhaja iz že znanega tonskega gradiva. Takt pred stevilko 31 je raztegnjen $\mathrm{v}$ trodoben takt, kjer klavir augmentirano ponovi zadnje tri tone $\mathrm{v}$ violini. Śtevilka 31 predstavlja pravo codo. Sestavljena je $i z$ istega plesnega motiva, le najprej ponovljenega $\mathrm{v} 5 / 8$ taktu, nato $\mathrm{v} 7 / 8$ taktu in razširjenega $\mathrm{s}$ štirimi šestnajstinkami $\mathrm{v}$ istem ritmu. Sledijo štirje takti $\mathrm{v} 3 / 8$ taktu, ki so grajeni svobodno in vodijo $\mathrm{v}$ poslednje tri takte $\mathrm{z}$ oznako tempa Largo. $\mathrm{V}$ treh taktih se tema razširi iz violine še $\mathrm{v}$ klavir in $\mathrm{v}$ oznaki dinamike ff se rapsodija tako zaključi.

Drugo rapsodijo je Lipovšek zasnoval na podlagi motivov štirih slovenskih ljudskih pesmi in enega plesnega motiva: "Sem mislil snoč' na vas iti", "Po gorah grmi in se bliska», "Ptica poje», "Srečali smo mravijo», "Grajski plesu. Oblikovno je rapsodija grajena enako kot prva, vendar bolj komplicirano in bolj zgoščeno.

Prvi del je, kot $\mathrm{v}$ prvi rapsodiji, tudi trodelen. Sestavljata ga prvi dve pesmi, v svoji osnovi umirjeni in tekoči. Del A je sestavljen iz treh period, ki obsegajo osem, devet in deset taktov $\mathrm{s}$ klavirskimi podaljški. $\mathrm{Da}$ jø skladatelj dobil celotno osemtaktno periodo, je osnovni ljudski material opisal tako, da je podaljšal tretji in četrti takt originala. Kot izpeljavni element je uporabil osminke $\mathrm{v}$ violinskem partu. Metrično je spremenil le tretji takt ljudske pesmi v štiridobni takt, ker so ponavljajoči se motivi nastali zunaj trodobne mere. Ena od zanimivosti je tudi ta, da je originalni začetek v durovi tonaliteti Lipovšek tu spremenil v molovo. $\mathrm{V}$ drugi periodi se pojavlja $7 / 8$ taktova mera in sicer zaradi neenakomerne metrike originala. $\mathrm{V}$ srednji periodi nastopa ritmična posebnost $\mathrm{v}$ obliki punktiranega ritma $\mathrm{v}$ violinskem, deloma tudi klavirskem partu. Druga in tretja perioda pomenita motivično sirjenje in razvijanje prve in tako se višek pojavi $\mathrm{v}$ tretjem delu, ko se celotni glasbeni tok ustavi na dinamicnem nižišču $\mathrm{s}$ tonom $\mathrm{es}^{3} \mathrm{v}$ violinskem partu. Klavirska spremljava $\mathrm{v}$ glavnem podpira ter tu in tam tudi dopolnjuje violinsko melodiko. Skladatelj se rad v njej poslužuje močnih akordov (kvart in nonakordov), ki jih najnje ritmično bogato razviti. Tako $\mathrm{v}$ violinski kot klavirski spremljavi $\mathrm{z}$ veckrat postavlja na izventonalne tone. "Po gorah se bliska in grmi" predstavlja del B. Ta je od vseh pesmi, ki jih je Lipovšek uporabil, najboljł 
komplicirana. Ne po svoji zgradbi, pač pa po vsebini. Originalna pesem vsebuje izredno notranjo ubranost in je izražena $\mathrm{s}$ tonalnimi toni. V sebi skriva prizadetost nad deževno gorsko pokrajino in je dejansko medi-
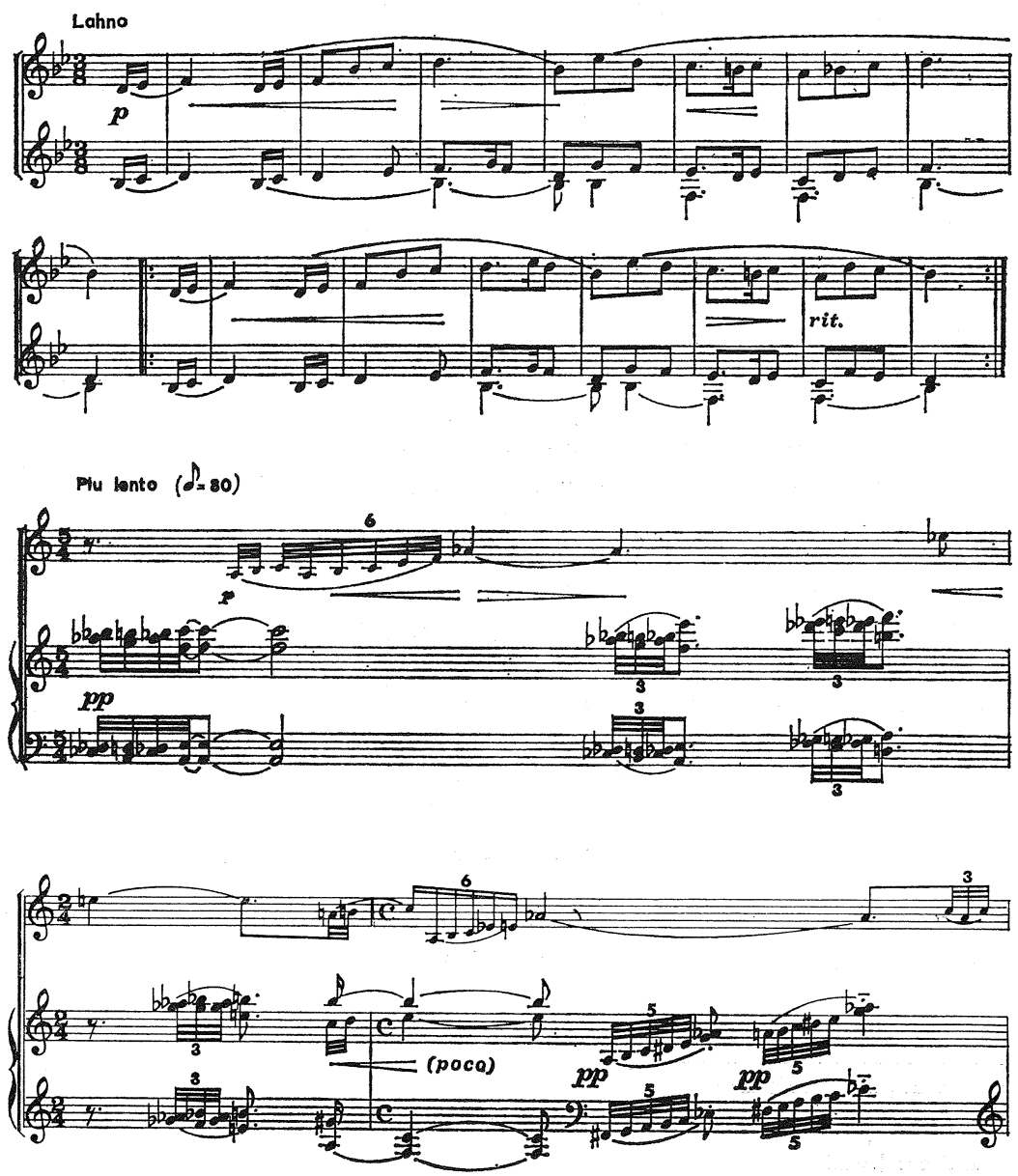

tacija oziroma kontemplacija človeka. V Lipovškovi modifikaciji je svojo prvotno podobo popolnoma spremenila. Izvirno $\mathrm{v}$ izgradnji silno preprosta $\mathrm{v} 3 / 8$ tekočem taktu, dolga le dve vrsti in napisana $\mathrm{v}$ durovi tonaliteti, je $v$ rapsodiji nenavadno spremenjena. Ritmična struktura je izredno razgibana, saj se metrum spreminja skoraj vsak takt. Takti pa so tudi notrauporabo triol, kratkih notnih vrednosti do dvaintridesetink in punktiranega ritma. Tudi dinamika izkazuje zadržanost pesmi. Razen enega crescenda $\mathrm{v}$ mf se vse odvija $\mathrm{v}$ okviru piana. Oblikovno je pesem zgrajena iz prvega dela, ki vsebuje sedem taktov in enotaktnega klavirskega dodatka in spremenjene ponovitve le-tega. Le-ta je oblikovno in ritmično zgoščena, tako da so od celotnih sedmih taktov zadnji sttirje le dodani in zgrajeni iz 
že znanega tkiva. Spremljava $\mathrm{v}$ njih je umirjenejša in poteka $\mathrm{v}$ tekočen osminskem gibanju. Celotna transformacija pesmi "Po gorah grmi in se bliskau izraža veliko skladateljevo osebno notranjo prizadetost, ki jo oblikuje s pomočjo vseh omenjenih sredstev. Po obeh periodah nastopijo trije takti $\mathrm{v}$ klavirski spremljavi, ki vodijo $\mathrm{v}$ ponoven nastop dela $\mathrm{A}$. Ta vsebuje transformirano prvo in drugo periodo ljudske pesmi, ki se odvija ves čas v violinskem partu, klavirska spremljava jo harmonsko dopolnjuje $\checkmark$ ritmičnem ostinatu osminskih triol. Pri številki 7 nastopi del $C$, ki je označen z malo hitrejšim tempom Poco più mosso del Tempo I. Predstavlja ga jasen citat pesmi "Ptica poje», vendar podaljšan v daljših tonskih vrednostih. Zato dobi globlji pomen kot ga ima v ljudski pesmi. Kot že večkrat doslej tudi tu klavirska spremljava komplementirano dopolnjuje violinsko melodijo. Celotna ritmična struktura je bolj umirjena od zgradbe v prejšnjem delu tako $v$ violinskem kot klavirskem deležu, vendar je bolj tekoča. Gradacija je izvedena v violinski melodiji na tonih $a, f, g, c$ in se $\mathrm{v}$ taktu pred številko 8 umakne v osnovno začetno tonaliteto F-dura. Vse do številke 9 Lipovšek relativno skromno osnovno glasbeno gradivo pesmi razvija in pripelje tik pred številko 9 do velike gradacije, ki jo doseže ne le s primerno dinamiko, ampak tudi z zgoščevanjem tonskega materiala tako $\mathrm{v}$ violini kot tudi klavirju. Zaradi narave ljudske pesmi tudi tu neprenehoma spreminja metrum, ki prav tako pripomore k zgoščevanju celotne strukture. Pri številki 9 se avtor posluži obratnega načina: v vsakem drugem taktu $\mathrm{v}$ klavirski spremljavi augmentira osnovno temo, medtem ko violinski part predstavlja prosti kontrapunkt. Vmesni takti so prekinitev glavne teme in so izpolnjeni $\mathrm{z}$ osminkami $\mathrm{v}$ violini, ki barvno le-te podpira. Sledi prehod štirinajst taktov, v katerem skladatelj spretno povezuje elemente prejšnje tematike $z$ elementi nove pesmi. Tudi tempo postane za malenkost hitrejši, od prej ostane večkratna vezava cetrtinke na osminko, glasbeni material se tonsko zgoščuje. Nato nastopi del D, ki je sestavljen trodelno iz pesmi "Srečali smo mravljo" in "Grajski ples».

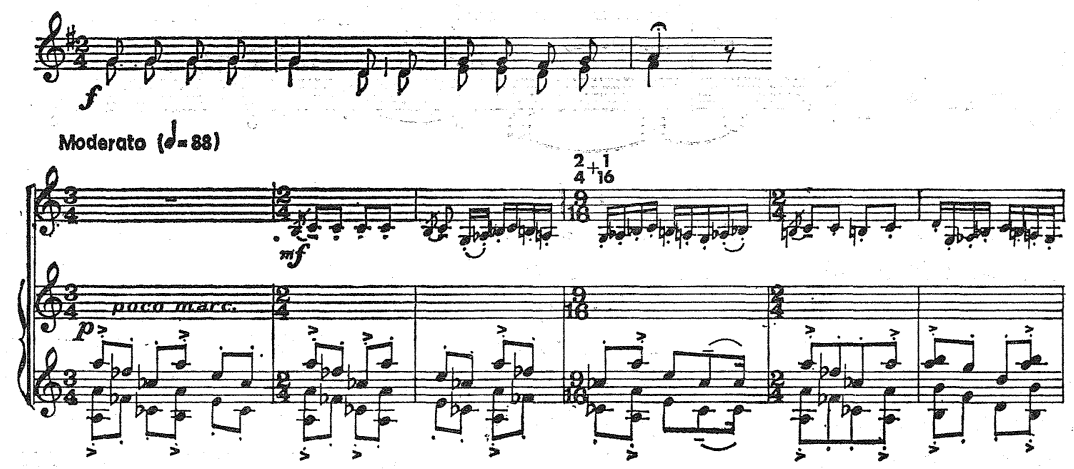

Zanimiva je transformacija medjimurske narodne pesmi. Četrti takt je v 9/16 taktu in predstavlja opisano prvotno melodijo; šestnajstinke vodijo v nadaljevanju prvega dvotaktja originalne pesmi. Takt vsebuje క̌estnaj- 
stinko več zaradi izrabe vseh not, nastala asimetrija pa bolj izstopa in poudarja bizarnost teksta. $\mathbf{S}$ tem želi skladatelj tonsko slikati besedilo. Klavirska spremljava predstavlja skoraj strogi ostinato, ki se ritmično razlikuje od takta do takta zaradi spreminjajočih se metričnih akcentov. Po enajstih taktih se prva perioda variirano $\mathrm{z}$ razvijanjem motivike po novi. Osnovne figure si klavirska spremljava in violina izmenjujeta. Metrika je izrazito asimetrična, saj je tretji takt $1 / 4$, ostali so pretežno $4 / 4$. $\mathrm{V}$ šestem taktu prevzame melodično vodstvo violina, motivični elementi izhajajo in se razvijajo iz klavirskega parta. Tu postaja spremljava gostejša in poteka $\mathrm{v}$ enakomernem šestnajstinskem gibanju z različnimi metričnimi poudarki. Sledi še ena ponovitev mravljine teme. Tokrat v Es-duru do kadence $v$ petem taktu po številki 13. Da tonsko gradivo ne bi postalo dolgočasno, nastopajo vmesni vrivki, ki celoto poživljajo. To so šestnajstinke, ki nadomeščajo osminke $\mathrm{v}$ originalu. Klavirska spremljava še vedno poteka $\mathrm{v}$ tekočem gibanju šestnajstinskih vrednosti. Po sedmih taktih spet prevzame vodilno vlogo klavir, ki $\mathrm{v}$ desni roki $\mathrm{v}$ oktavnem razmaku prinese glavno temo. Po prehodu treh taktov nastopi pri številki 14 »Grajski plesı. Skladatelj se tu morda najverneje drži osnovne predloge, vsaj v za-
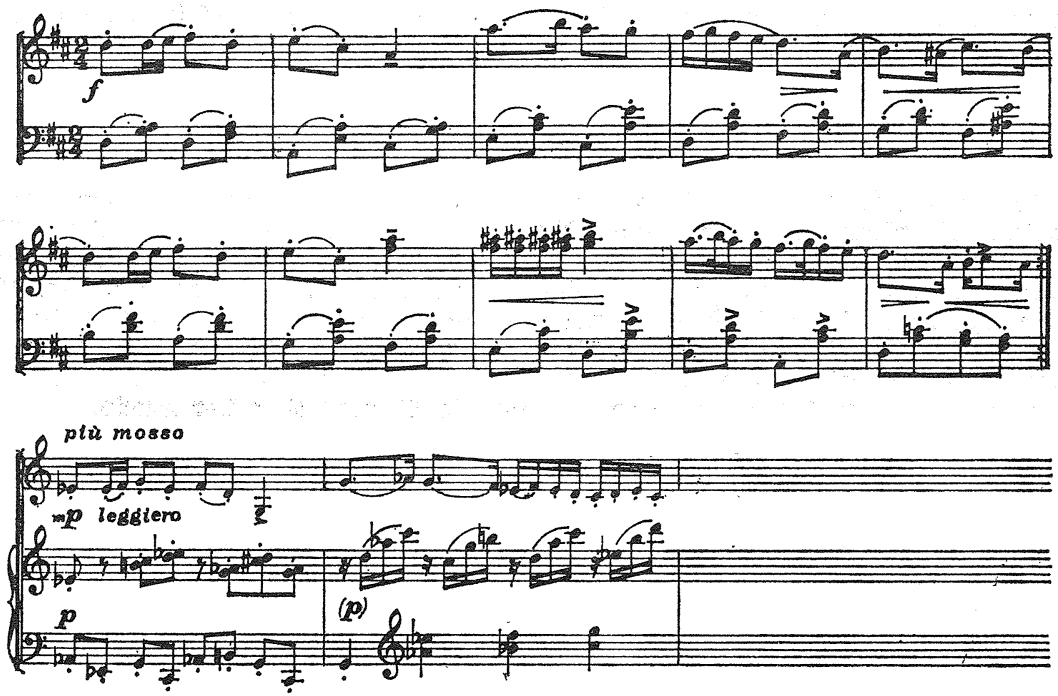

četku; le $\mathrm{v}$ originalu je $2 / 4$, tu $4 / 4$ takt. Poleg tega so $\mathrm{v}$ rapsodiji tudi premaknjeni akcenti; $s$ tem se material zgoščje in prihaja do večje intenzivnosti. Osnovna tematika "Grajskega plesa" se razvija v osmih taktih, nato sledi kratki enotaktni $7 / 8$ prehod $v$ klavirju $\mathrm{k}$ zanimivemu razvijanju obeh tem mravlje in plesa vse do konca rapsodije. Ker sta oba osnovna motiva podobna, ju je Lipovšek dopolnjeval in formiral večkratne hitre prehode iz motiva v motiv. Dvanajst taktov pred številko 15 se razvija tematika mravlje, nakar spet sledi jasna tema plesa $\mathrm{v}$ violini. Toda istočasno se $\mathrm{v}$ tenorju spremljave oglašajo z označenimi akcenti glavni toni mravlje. To je domiselna kombinacija obeh tem, kar zaradi svoje gostote 
nakazuje bližajočo se codo. Osmi takt po številki 15 je svobodna kadenca (torej izven tonalnih centrov) $\mathrm{v}$ območje C-dura, kjer violina in basovska linija klavirja $\mathrm{v}$ unisonu ponovno prineseta "Grajski ples». Toda le tri njegove takte, kajti že sledi kadenčni klavirski prehod v codo. Coda vsebuje elemente obeh tem, vendar pretežno mravlje. Najprej nastopa v violini razvita tema mravlje $\mathrm{v}$ šestnajstinskem toku, ki pa se odvija skupno s klavirjem. Efektni so skupni sklepi na glavnih kadenčnih poudarkih in sovpadajo s tekstom oziroma ga poudarjajo: usmo rekli ji gospa; ker taksne tanke noge 'ma«. Po prosti kadenci sledi korona ter zaključek sedem taktov v Presto tempu. V violini vsebuje delno elemente plesnega motiva, nato pa skupno s klavirsko spremljavo prevzame značaj motiva mravlje z značilnim sinkopiranim ritmom.

Natančni pregled obeh rapsodij kaže da sta skladbi tako vsebinsko kot glede na samo zgradbo izredno dognani. Izbira narodnih napevov gotovo ni le izraz avtorjeve afinitete, ampak tudi posledica premišljenosti $\mathrm{v}$ oblikovanju. Komplicirane metrične spremembe, ki jih vsebujejo izvirne pesmi, so $\mathrm{v}$ obeh skladbah rešene zanimivo, periode so asimetrične in brez odvečnih ponavljanj. Ceravno se notranja in zunanja oblikovna simetrija ne občuti, sta $\mathrm{v}$ bistvu prva kot druga Lipovškova rapsodija koncipirani in tudi izpeljani strogo in dosledno.

\section{SUMMARY}

The two rhapsodies for violin and piano occupy an important position among Marijan Lipovšek's chamber works. The first of the two was composed in 1955, the second in 1962. As regards the form Lipovšek follows Bartók's rhapsodic examples, however, expanding the binary form into tripartite realizations. The basic motivic material is drawn from folk songs. In spite of the metrically and melodically complicated structure Lipovšek is consistent in his ways of transforming. Nevertheless, the essence of the folk tunes remains unchanged. Both rhapsodies represent a valuable contribution to slovene chamber music. 